\title{
Application and Research of Improved AHP Model in Employment of College Students
}

\author{
Miao Zhang*
}

Communist Youthleage, Zhejiang University Of Finance Economics, Hangzhou, 310018, Zhejiang, China

\begin{abstract}
Employment is a problem faced by every fresh graduate. Graduates from different majors choose the right job according to their own situations. However, typically graduates would find it difficult to make judgments of jobs, thus missing out their most appropriate chances. In this paper, the AHP model is introduced to state the problems encountered by graduates and the relevant factors that affect their employment results. In addition, a rating system is established and a comparative matrix is constructed based on the survey data. The conclusion proves that the AHP model is a feasible scheme used to resolve employment problems, and that it is viable to use the mathematical model to solve complex decision problem in the real world. However, a more realistic model on the basis of large amounts of data should be constructed in this paper, which is regretfully not built here given the limited sample size.
\end{abstract}

Keywords: AHP, decision, employment, weight vector.

\section{INTRODUCTION}

In recent years, in the light of the expansion of university student enrollment, the number of undergraduates increase year by year, and business employers have higher requirements for academic background of employees. In this context, college student employment has been increasingly difficult [1-4]. However, fresh graduates have grandiose aims but puny abilities when confronting career challenges and don't like working in SMEs. They are lack of rational judgment of job opportunities and a good understanding of themselves.

This paper conducts a questionnaire survey to know the mental state of general college students when choosing a job and analyzes various factors they consider in employment, with the purpose of seeking comprehensive evaluation methods to help them make selections.

\section{AHP}

\subsection{Proposal of AHP}

The Analytical Hierarchy Process (AHP) model is a multi-objective decision analytic methodology that combines qualitative and quantitative analyses [5-8]. It absorbs and utilizes characteristics of behavioral science and quantifies experience-based judgments of decision makers. In the case of complex structure of targets (factors) and a lack of necessary data, it is practical to use this method, which a commonly applied system analysis method in systems science, and therefore it becomes one of the mathematical tools for systems analysis.

\subsection{Theory and Step of the AHP Model}

\subsubsection{Establishment of the Recursive Hierarchy Structure}

When applying AHP to resolve practical problems, the first thing to do is analyze the decision problem $[9,10]$, put it well-organized and hierarchical, and sort the recursive hierarchical structure.

The hierarchical structure required by the AHP model consists of the following three levels:

The target level (the highest level): predetermined target of the problems;

The criteria level (intermediate level): criteria that affect the realization of the target;

The measure level (the lowest level): measures to achieve the target;

By analyzing the complex problems, the first is to determine the target of decision making and take the target as the element in the target level (the highest level); the target requirements are unique, which is the target level only has one element.

Afterwards, identify the criteria that affect the realization of the target, taking it as the element in the criteria level under the target level. In complex problems, there are many criteria that affect the realization of the target. At this time one should make a detailed analysis of the correlation between various criteria elements. In other words, some are the main criteria while some are secondary criteria affiliated with the major criteria. Then, according to these relationships, divide criteria elements into different levels and groups, and generally elements at different levels have a relationship of administrative subordination. That is, the upper level of elements is composed of by the next level and dominates the next level of elements. Elements at the 
same level constitute several groups, and elements in the same group exhibit similar properties and generally attach to the same upper-level elements (dominated by upperlevel element). Different groups of elements show different properties and generally attach to different upper-level elements.

In the complex hierarchical structure, sometimes group's relationship is not obvious. That is, several upper-level elements play a dominant role to several lower-level elements at the same time and form the overlapping hierarchical relationship. Anyway, the upper-lower affiliation should be obvious.

Finally, analyze what the final solutions (measures) are and take them as elements in the measure level right at the bottom of the hierarchical structure (the lowest level), in order to solve the decision problem (achieve the decision goal), under the above criteria.

Clarify the elements at each level and their positions, and connect them by using lines, thus constituting the hierarchical structure.

\subsubsection{Construction of Judgment Matrix and Assignment}

The judgment matrix can be easily constructed according to the hierarchical structure.

The method of constructing the judgment matrix is: each element that has a downward affiliation (called criteria) as the first element of the judgment matrix (upper left corner), and each element subordinating to it are arranged in the first row and first column subsequently after it.

It is important to fill the judgment matrix. Methods to fill the judgment matrix include:

Expert consultation: consult experts, attach values (1-9) corresponding to the importance degree of elements compared by experts, as shown in Table $\mathbf{1}$.

Table 1. Meanings of importance scales.

\begin{tabular}{|c|l|}
\hline $\begin{array}{c}\text { Scale of } \\
\text { Importance }\end{array}$ & \multicolumn{1}{c|}{ Meanings } \\
\hline \hline 1 & The two elements are equally important \\
\hline 3 & $\begin{array}{l}\text { The former element is slightly more important than the } \\
\text { latter }\end{array}$ \\
\hline 5 & $\begin{array}{l}\text { The former element is obviously more important than } \\
\text { the latter }\end{array}$ \\
\hline 7 & $\begin{array}{l}\text { The former element is strongly more important than } \\
\text { the latter }\end{array}$ \\
\hline 9 & $\begin{array}{l}\text { The former element is extremely more important than } \\
\text { the latter }\end{array}$ \\
\hline $2,4,6,8$ & Median of the above judgment \\
\hline Reciprocal & $\begin{array}{l}\text { If the ratio of importance of element } \mathrm{I} \text { and importance } \\
\text { of element } \mathrm{j} \text { is } \mathrm{a}_{\mathrm{ij}}, \text { the ratio of importance of element } \mathrm{j} \\
\text { and the importance of element } \mathrm{I} \text { is } \mathrm{a}_{\mathrm{ji}}=1 / \mathrm{a}_{\mathrm{ij}} \text {. }\end{array}$ \\
\hline
\end{tabular}

Assume that the judgment matrix after filling is $\mathrm{A}=\left(\mathrm{a}_{\mathrm{ij}}\right)_{\mathrm{n} \times \mathrm{n}}$, the judgment matrix has the following properties:
(1) aij $>0$
(2) aji $=1 /$ aji
(3) aii $=1$

According to the above properties, the judgment matrix features symmetry, and therefore when filling this out, usually fill $a_{\mathrm{ii}}=1$ first and then only judge and fill the $n(n-1) / 2$ elements of the upper triangle or the lower triangular.

Under special circumstances, the judgment matrix has transitivity property, which is to satisfy the equation: $\mathrm{a}_{\mathrm{ij}}{ }^{*} \mathrm{a}_{\mathrm{jk}}=\mathrm{a}_{\mathrm{ik}}$.

When the equation has been established for all the elements in the judgment matrix, the judgment matrix is then called the consistency matrix.

\subsubsection{Single Hierarchical Arrangement (Computing the Weight Vector) and Inspection}

For the judgment matrix filled out by experts, some sort of mathematical methods are used for hierarchical arrangement.

The single hierarchical arrangement refers to the relative weight of each judgment matrix element for the criteria, so it is essentially computing the weight vector. There are many methods to calculate the weight vector, including characteristic roots method, normalization method, roots method, power method, etc. Here the normalization method is briefly introduced.

The principle of the normalization method is that for a consistent judgment matrix, the corresponding weights are gained after normalizing each column. For an inconsistent judgment matrix, approximate weights are gained after normalizing each column. For vectors of $n$ columns, the arithmetic mean value is computed as the final weight. The specific formula is:

$$
W_{i}=\frac{1}{n} \sum_{j=1}^{n} \frac{a_{i j}}{\sum_{k=1}^{n} a_{k l}}
$$

It should be noted that, in the arrangement layer upon layer, consistency check should be carried out on the judgment matrix.

In special circumstances, the judgment matrix may have transitivity and consistency. Under normal circumstances, the judgment matrix may not need to strictly meet these properties. But from man's cognition principles, the importance arrangement of a correct judgment matrix should present certain logical laws. For example, if $\mathrm{A}$ is more important than $\mathrm{B}$, and $\mathrm{B}$ is more important than $\mathrm{C}$, from a logical point of view, A should be significantly more important than C. If conducting pairwise comparisons and $\mathrm{A}$ is more important than $\mathrm{C}$, then the judgment matrix has violated the consistency criterion, which is logically unreasonable.

Therefore, in practice, the judgment matrix should largely meet the consistency and it is necessary to carry out consistency check. Only by testing can people prove the 
judgment matrix to be logically reasonable and continue analyzing the results.

The step of consistency test is as follows.

First, calculate the consistency index C.I.

C.I. $=\frac{\lambda_{\max }-n}{n-1}$

Second, look up the table to determine the appropriate mean random consistency index R.I.

According to the different orders of the judgment matrix, look up the table below, and the mean random consistency index R.I. is obtained. For example, for the fifth-order judgment matrix, look up the table and R.I. $=1.12$ is obtained.

Third, calculate the consistency ratio C.R. and make a judgment

C.R. $=\frac{\text { C.I. }}{\text { R.I. }}$

When C.R. $<0.1$, it is considered that the consistency of the judgment matrix is acceptable; when C.R.> 0.1 , it is considered that the judgment matrix does not meet the consistency requirements and should be re-modified.

\subsubsection{The Total Level Arrangement and Inspection}

The total arrangement refers to the relative weight of each judgment matrix element for the target level (the highest level), and the weight is calculated from the top down and synthesized layer by layer.

Obviously, the single hierarchical arrangement at the second level is the total hierarchical arrangement result. Assume that the weight of element $\mathrm{m}$ at the $\mathrm{k}-1$ level with respect to the total target weight has been computed: $\mathrm{w}^{(\mathrm{k}-1)}=\left(\mathrm{w}_{1}{ }^{(\mathrm{k}-1)}, \mathrm{w}_{2}{ }^{(\mathrm{k}-1)}, \ldots, \mathrm{w}_{\mathrm{m}}{ }^{(\mathrm{k}-1)}\right)^{\mathrm{T}} ;$ the single hierarchical arrangement weight of element $\mathrm{n}$ at the $\mathrm{k}$ level with respect to element $\mathrm{j}$ at the upper level ( $\mathrm{k}$ level) is $\mathrm{p}_{\mathrm{j}}{ }^{(\mathrm{k})}=\left(\mathrm{p}_{1 \mathrm{j}}{ }^{(\mathrm{k})}, \mathrm{p}_{2 \mathrm{j}}{ }^{(\mathrm{k})}, \ldots, \mathrm{p}_{\mathrm{nj}}{ }^{(\mathrm{k})}\right)^{\mathrm{T}}$, where the weight of elements not subjecting to element $\mathrm{j}$ is zero. Make $\mathrm{P}^{(\mathrm{k})}=\left(\mathrm{p}_{1}{ }^{(\mathrm{k})}, \mathrm{p}_{2}{ }^{(\mathrm{k})}, \ldots, \mathrm{p}_{\mathrm{n}}{ }^{(\mathrm{k})}\right)$, it represents the arrangement of element $\mathrm{k}$ at the level of k-1. Then the overall arrangement of elements at level $\mathrm{k}$ with respect to the total target is:

$\mathrm{w}^{(\mathrm{k})}=\left(\mathrm{w}_{1}{ }^{(\mathrm{k})}, \mathrm{w}_{2}{ }^{(\mathrm{k})}, \ldots, \mathrm{w}_{\mathrm{n}}{ }^{(\mathrm{k})}\right)^{\mathrm{T}}=\mathrm{p}^{(\mathrm{k})} \mathrm{w}^{(\mathrm{k}-1)}$

Or $w_{i}^{(k)}=\sum_{j=1}^{m} p_{i j}{ }^{(k)} w_{j}^{(k-1)} \quad \mathrm{I}=1,2, \ldots, \mathrm{n}$
Similarly, it is also necessary to conduct the consistency check of the overall arrangement results.

Suppose C.I. ${ }^{(k)}{ }^{(k)}$ R.I. $_{\cdot j}{ }^{(k)}$ and C.R. ${ }_{\cdot j}{ }^{(k)}, j=1,2, \ldots, m$ with criteria of element $\mathrm{j}$ at the $\mathrm{k}-1$ level has been calculated, the comprehensive test Index of the level $\mathrm{k}$ is:

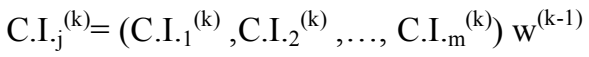

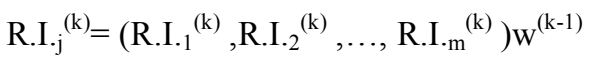

$$
\begin{aligned}
& C \cdot R^{(k)}=\frac{C . I .^{(k)}}{R . I .^{(k)}}
\end{aligned}
$$

When C.R. ${ }^{(\mathrm{k})}<0.1$, it is considered that the overall consistency of the judgment matrix is acceptable.

\subsubsection{Analysis}

The final decision scheme is obtained by analyzing the arrangement results.

\section{PRACTICAL APPLICATIONS}

\subsection{Proposal of Problems}

For a college graduate, finding a suitable job is a problem urgently needed to tackle. When a graduate looks for a job, he has three choices to make after handing in resume and having interviews, among others. The choices are: B1 (Anyuan Coal Industry Group Co., Ltd.), B2 (Asustek Computer Inc.), and B3 (China Petrochemical Corporation). How to select a satisfactory job from the three offers? It is to be resolved. Through research, four criteria are eventually identified as references to determine the most suitable and most satisfactory job offer.

Criteria: at the criterion level A, namely the development prospect $\mathrm{A} 1$, economic income $\mathrm{A} 2$, firm reputation $\mathrm{A} 3$, geographical location A4; the most satisfying work is judged through these four criteria.

\subsection{Model Assumptions}

(1) This is a liberal arts graduate student who also minor in lots of science subjects in college, so he is proficient in both arts and sciences.

(2) Three units have the same objective conditions for the graduate.

(3) The graduate is qualified for these three jobs.

Table 2. Mean random consistency index R.I. (1000 times computation result of reciprocal judgment matrix).

\begin{tabular}{|c|c|c|c|c|c|c|c|c|}
\hline Matrix Order & 1 & 2 & 3 & 4 & 5 & 6 & 7 & 8 \\
\hline R.I. & 0 & 0 & 0.52 & 0.89 & 1.12 & 1.26 & 1.36 & 1.41 \\
\hline Matrix Order & 9 & 10 & & & & & 14 & 15 \\
\hline R.I. & 1.46 & 1.49 & & & & & 1.58 & 1.59 \\
\hline
\end{tabular}




\subsection{Symbol Description}

Table 3. Parameter description.

\begin{tabular}{|c|c|}
\hline$\lambda$ & The maximum characteristic root \\
\hline$N$ & Pairwise comparison of comparison matrix order \\
\hline$w$ & Eigenvalue corresponding to the maximum characteristic root \\
\hline$C I$ & Consistency Index \\
\hline$R I$ & Random Consistency Index \\
\hline$C R$ & Consistency ratio \\
\hline
\end{tabular}

\subsection{Establishment of the Hierarchy Structure Model}

Level One: the target layer Z, which is satisfaction $\mathrm{Z}$ with alternative jobs;

Level Two: the criterion level A, namely the development prospect $\mathrm{A} 1$, economic income $\mathrm{A} 2$, firm reputation $\mathrm{A} 3$, geographical location A4;

Level Three: Scheme B, which is B1 (Anyuan Coal Industry Group Co., Ltd.), B2 (Asustek Computer Inc.), and B3 (China Petrochemical Corporation). The structure figure established is:

\subsection{Construction of Pairwise Comparison Matrix}

First there questionnaires are distributed to students whose ranking is $10 \%, 30 \%, 60 \%$ in class, and a statistical comparative analysis is made for pairwise comparison matrix at the target level and the criterion level. The three respondents respectively write that the pairwise comparison matrix at the target level and the criterion level, as shown below:

(Each cell is denoted as $a_{i j}=A_{i} / A_{j}$, namely the ratio of corresponding values in rows and in columns.
Table 4. Opinion survey 1.

\begin{tabular}{|c|c|c|c|c|}
\hline $\mathbf{Z}$ & $\mathbf{A 1}$ & $\mathbf{A 2}$ & $\mathbf{A 3}$ & $\mathbf{A 4}$ \\
\hline \hline $\mathrm{A} 1$ & 1 & 1 & 5 & 5 \\
\hline $\mathrm{A} 2$ & 1 & 1 & 3 & 5 \\
\hline $\mathrm{A} 3$ & $1 / 5$ & $1 / 3$ & 1 & 2 \\
\hline $\mathrm{A} 4$ & $1 / 5$ & $1 / 5$ & $1 / 2$ & 1 \\
\hline
\end{tabular}

Table 5. Opinion survey 2.

\begin{tabular}{|c|c|c|c|c|}
\hline $\mathbf{Z}$ & $\mathbf{A 1}$ & $\mathbf{A 2}$ & $\mathbf{A 3}$ & $\mathbf{A 4}$ \\
\hline \hline $\mathrm{A} 1$ & 1 & 2 & 3 & 5 \\
\hline $\mathrm{A} 2$ & $1 / 2$ & 1 & 3 & 3 \\
\hline $\mathrm{A} 3$ & $1 / 3$ & $1 / 3$ & 1 & 2 \\
\hline $\mathrm{A} 4$ & $1 / 5$ & $1 / 3$ & $1 / 2$ & 1 \\
\hline
\end{tabular}

Table 6. Opinion survey 3.

\begin{tabular}{|c|c|c|c|c|}
\hline $\mathbf{Z}$ & $\mathbf{A 1}$ & $\mathbf{A 2}$ & $\mathbf{A 3}$ & $\mathbf{A 4}$ \\
\hline \hline $\mathrm{A} 1$ & 1 & 3 & 2 & 3 \\
\hline $\mathrm{A} 2$ & $1 / 3$ & 1 & $1 / 2$ & 1 \\
\hline $\mathrm{A} 3$ & $1 / 2$ & 2 & 1 & 3 \\
\hline $\mathrm{A} 4$ & $1 / 3$ & 1 & $1 / 3$ & 1 \\
\hline
\end{tabular}

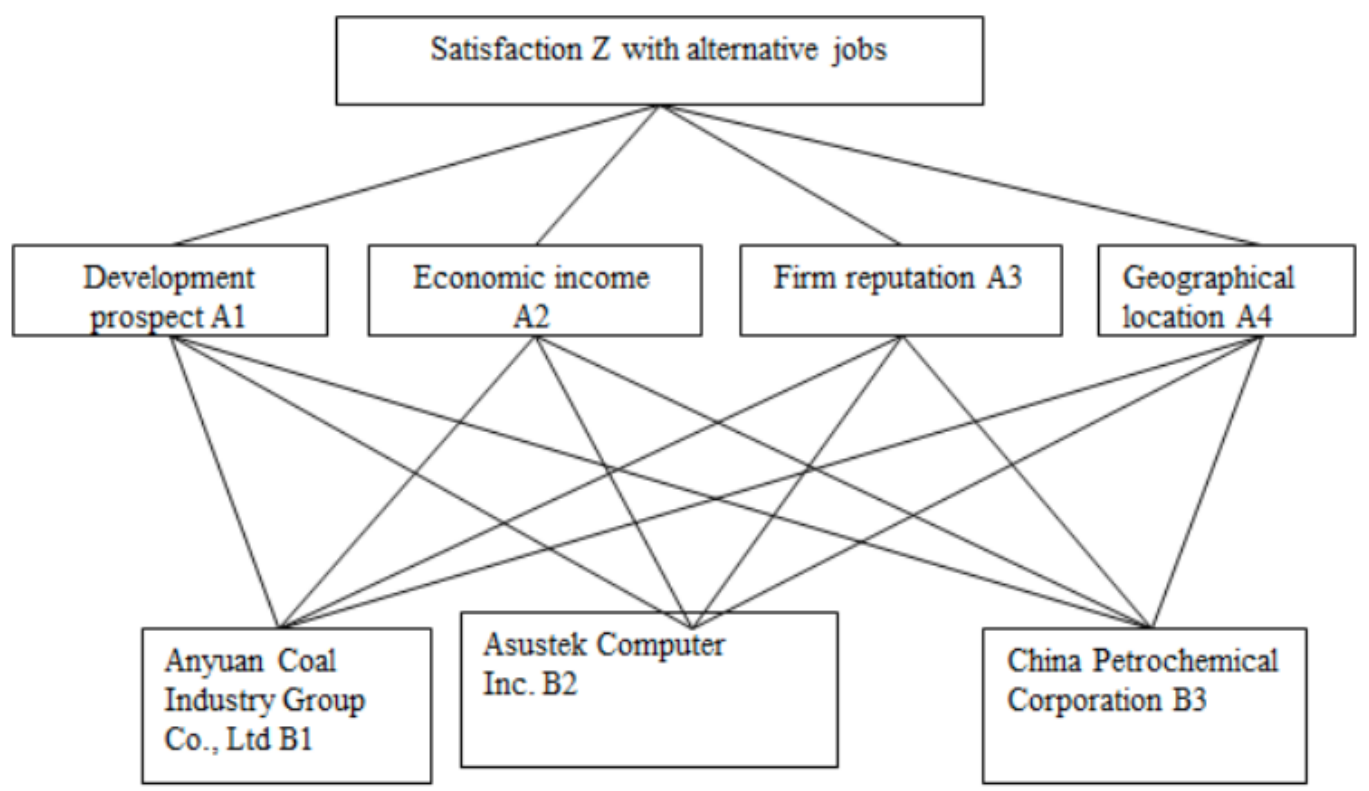

Fig. (1). Hierarchy structure. 
As per the formula $a_{i j}=\sqrt[3]{\prod_{k=1}^{3} a_{i j k}}, i ! j=1,2,3$, the geometric mean of $a_{i j}$ is calculated and the inverse symmetric matrix A is:

$$
A=\left[\begin{array}{cccc}
1 & \sqrt[3]{6} & \sqrt[3]{30} & \sqrt[3]{75} \\
\frac{1}{\sqrt[3]{6}} & 1 & \sqrt[3]{4.5} & \sqrt[3]{15} \\
\frac{1}{\sqrt[3]{30}} & \frac{1}{\sqrt[3]{4.5}} & 1 & \sqrt[3]{12} \\
\frac{1}{\sqrt[3]{75}} & \frac{1}{\sqrt[3]{15}} & \frac{1}{\sqrt[3]{12}} & 1
\end{array}\right]
$$

Similarly, the comparison inverse symmetric matrix between the target level C and the criterion level B is as follows:

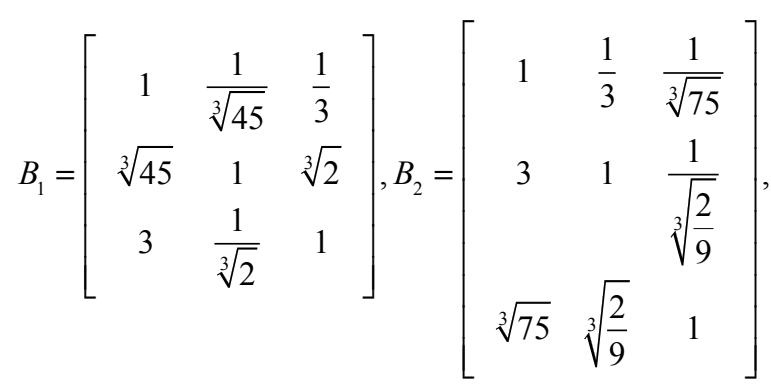

$$
B_{3}=\left[\begin{array}{ccc}
1 & \sqrt[3]{45} & \sqrt[3]{6} \\
\frac{1}{\sqrt[3]{45}} & 1 & \frac{1}{\sqrt[3]{75}} \\
\frac{1}{\sqrt[3]{6}} & \sqrt[3]{75} & 1
\end{array}\right], B_{4}=\left[\begin{array}{ccc}
1 & \sqrt[3]{18} & \frac{1}{\sqrt[3]{2}} \\
\frac{1}{\sqrt[3]{18}} & 1 & \frac{1}{\sqrt[3]{36}} \\
\sqrt[3]{2} & \sqrt[3]{36} & 1
\end{array}\right]
$$

3.6. Calculation of Weight Vectors of Single Hierarchical Arrangement and Consistency Check

By the known pairwise comparison matrix $A$, matlab program is used to calculate the weight vector of $A$ with respect to the target level Z:

$\omega=\{0.4987,0.2745,0.2268,0.0949\}$

To measure whether the results can be accepted, Satie constructed the most inconsistent case, in which the n comparison matrix for several different matrices takes the random access method $1 / 9,1 / 7, \ldots \ldots .7,9$, and 100-500 subsamples are used on different $\mathrm{n}$ to compute its consistency index, and then obtain the average value, denoted as RI.

Referring the random consistency index as shown in Table 4:

Calculate the relevant value of the matrix A:

$\mathrm{CI}=0.0719, \mathrm{RI}=0.90, \mathrm{CR}=\mathrm{CI} / \mathrm{RI}=0.0799<0.1$

Then it is considered the matrix A has passed the consistency test.

Similarly, for pairwise comparison matrices $\mathrm{B}_{1}, \mathrm{~B}_{2}, \mathrm{~B}_{3}$, $\mathrm{B}_{4}$ the above-described method is used to gain the weight vector with respect to the Level A and carry out the consistency test, with results shown below:

From the results, it can be found that $\mathrm{B}_{1}, \mathrm{~B}_{2}, \mathrm{~B}_{3}, \mathrm{~B}_{4}$ have passed the consistency test, and the corresponding weights are acceptable.

\subsection{Calculation of Overall Hierarchical Arrangement Weight and Consistency Test}

The weight of the criterion level A to the target level $\mathrm{Z}$ has been obtained, as well as the weight of the measure level $\mathrm{B}$ to the criterion level $\mathrm{A}$, and the overall hierarchical arrangement weight of the measure level $\mathrm{C}$ to the target level $\mathrm{Z}$.

The consistency ratio of the overall hierarchical arrangement is:

Table 7. Random consistency index.

\begin{tabular}{|c|c|c|c|c|c|c|c|c|c|c|c|}
\hline $\mathbf{n}$ & $\mathbf{1}$ & $\mathbf{2}$ & $\mathbf{3}$ & $\mathbf{4}$ & $\mathbf{5}$ & $\mathbf{6}$ & $\mathbf{7}$ & $\mathbf{8}$ & $\mathbf{9}$ & $\mathbf{1 0}$ & $\mathbf{1 1}$ \\
\hline \hline $\mathrm{RI}$ & 0 & 0 & 0.58 & 0.90 & 1.12 & 1.24 & 1.32 & 1.41 & 1.45 & 1.49 & 1.51 \\
\hline
\end{tabular}

Table 8. Consistency test results.

\begin{tabular}{|c|c|c|c|c|}
\hline $\mathbf{A}$ & $\mathbf{1}$ & $\mathbf{2}$ & $\mathbf{3}$ & $\mathbf{4}$ \\
\hline \hline$\omega_{k 1}$ & 0.1321 & 0.1226 & 0.5185 & 0.3768 \\
\hline$\omega_{k 2}$ & 0.4795 & 0.4869 & 0.1129 & 0.1485 \\
\hline$\omega_{k 3}$ & 0.3884 & 0.3905 & 0.3686 & 0.4747 \\
\hline$C I_{k}$ & $1.5947 \mathrm{e}-004$ & 0.0396 & 0.0329 & 0.0166 \\
\hline$R I_{k}$ & 0.58 & 0.58 & 0.58 & 0.58 \\
\hline$C R_{k}$ & $2.7495 \mathrm{e}-004$ & 0.0683 & 0.0566 & 0.0287 \\
\hline
\end{tabular}


Table 9. Overall hierarchical arrangement weight.

\begin{tabular}{|c|c|c|c|c|c|}
\hline \multirow{2}{*}{ Level B } & $\mathbf{A}_{1}$ & $\mathbf{A}_{2}$ & $\mathbf{A}_{3}$ & $\mathbf{A}_{4}$ & \multirow{2}{*}{$\begin{array}{c}\text { Overall Hierarchical } \\
\text { Arrangement Weight at Level B } \\
\qquad\left(\sum_{j=1}^{4} b_{i j} a_{j}\right)\end{array}$} \\
\hline & $a_{I}=0.4987$ & $a_{2}=0.2745$ & $a_{3}=0.2268$ & $a_{4}=0.0949$ & \\
\hline $\mathrm{B}_{1}$ & 0.1321 & 0.1226 & 0.5185 & 0.3768 & 0.2529 \\
\hline $\mathrm{B}_{2}$ & 0.4795 & 0.4869 & 0.1129 & 0.1485 & 0.4125 \\
\hline $\mathrm{B}_{3}$ & 0.3884 & 0.3905 & 0.3686 & 0.4747 & 0.4295 \\
\hline
\end{tabular}

$C R=\frac{a_{1} C I_{1}+a_{2} C I_{2}+a_{3} C I_{3}+a_{4} C I_{4}}{a_{1} R I_{1}+a_{2} R I_{2}+a_{3} R I_{3}+a_{4} R I_{4}}=0.0200<0.1$

Hence, the overall hierarchical arrangement has passed the consistency test, $\omega=\{0.2529,0.4125,0.4295\}$ can be used as a basis for making final decisions.

Since $0.4295>0.4125>0.2529$, namely B3 $>$ B2 $>$ B1, China Petrochemical Corporation is preferred after comprehensively weighing and balancing, followed by Asustek Computer Inc. and lastly Anyuan Coal Industry Group Co., Ltd. Visibly, when college graduates meet multiple job offers and it is difficult to make a choice, this method is available for decision-making.

\section{CONCLUSION}

In a series of standardized operations, it is found that the most important factor affecting graduates' job decision is development prospect, which also reflects whether the individual value can be better reflected. The next is economic condition, firm reputation and geographical location. It fully demonstrates that as of today's university students, career selection is not only a way to make a living, but also to play individual strengths, seek personal value and pursue their dreams.

In real life, for better and faster employment, sometimes a series of factors such as remuneration package, development prospects and geographical location influence graduates' selection of jobs. When they are temporarily unable to make the right choice, they should turn to the appropriate method for decision-making, which is what kind of work is more suited to their interests and can bring individual expertise.

When choosing a job, set forth from reality rather than just paying attention to salary. Be far-sighted and make longterm plans for personal career instead of blindly choosing a job for the sake of the present interests. When looking for a job, give full play to initiative and enthusiasm. Be realistic in our self-estimation, neither being conceited nor belittling ourselves. Make a reasonable and comprehensive analysis and evaluation of ourselves and have confidence. Always make self-education, self-learning, so as to obtain better allround development.

\section{CONFLICT OF INTEREST}

The author confirms that this article content has no conflict of interest.

\section{ACKNOWLEDGEMENTS}

Declared none.

\section{REFERENCES}

[1] C. M. Kalenkoski, and W. P. Sabrina, "Time to work or time to play: The effect of student employment on homework, sleep, and screen time," Labour Economics, vol. 19, no. 2, pp. 211-221, 2012.

[2] S. R. Porter, "Do college student surveys have any validity?," The Review of Higher Education, vol. 35, no. 1, pp. 45-76, 2011.

[3] M. Mona, D. Farrell, and D. Barton, "Education to employment: Designing a system that works," Dominic Barton, 2012.

[4] C. Avery, and T. Sarah, "Student Loans: Do College Students Borrow Too Much-Or Not Enough?," The Journal of Economic Perspectives, pp. 165-192, 2012.

[5] H. R. Pourghasemi, B. Pradhan, and C. Gokceoglu, "Application of fuzzy logic and analytical hierarchy process (AHP) to landslide susceptibility mapping at Haraz watershed, Iran," Natural Hazards, vol. 63, no. 2, pp. 965-996, 2012.

[6] A. Yalcin, S. Reis, A. C. Aydinoglu, and T. Yomralioglu, "A GISbased comparative study of frequency ratio, analytical hierarchy process, bivariate statistics and logistics regression methods for landslide susceptibility mapping in Trabzon, NE Turkey," Catena, vol. 85 , no. 3, pp. 274-287, 2011.

[7] T. J. Barker, and B. Z. Zelda, "A multicriteria decision making model for reverse logistics using analytical hierarchy process," Omega, vol. 39, no. 5, pp. 558-573, 2011.

[8] O. Althuwaynee, B. Pradhan, and H. J. Park, "A novel ensemble bivariate statistical evidential belief function with knowledge-based analytical hierarchy process and multivariate statistical logistic regression for landslide susceptibility mapping," Catena, vol. 114, pp. 21-36, 2014.

[9] R. D. Raut, and C. M. Vaishali, "A new strategic approach of fuzzy-quality function deployment and analytical hierarchy process in construction industry," International Journal of Logistics Systems and Management, vol. 20, no. 2, pp. 260-290, 2015.

[10] A. B. Borade, G. Kannan, and S. V. Bansod, "Analytical hierarchy process-based framework for VMI adoption," International Journal of Production Research, vol. 51, no. 4, pp. 963-978, 2013. 